Arti Hurria, Kayo Togawa, Smita Bhatia, Rupal Ramani, and F. Lennie Wong, City of Hope Comprehensive Cancer Center and Beckman Research Institute, Duarte; Kurt Hansen, University of California Davis School of Medicine, Sacramento, CA; Supriya G. Mohile, University of Rochester Medical Center, Rochester; Stuart M. Lichtman, Shira Klapper, and William P. Tew, Memorial Sloan-Kettering Cancer Center; Mark Lachs, Weill Cornell Medical College,

New York; Ajeet Gajra, State University of New York Upstate Medical Univer-

sity and Veterans Administration Medical Center, Syracuse, NY; Cynthia

Owusu, Case Western Reserve University, Cleveland, OH; Heidi D. Klepin,

Wake Forest University School of Medicine, Winston-Salem, NC; Cary P.

Gross, Yale Comprehensive Cancer Center, New Haven, CT; and Vani Katheria, Georgetown University, Washington, DC.

Submitted February 10, 2011; accepted May 30, 2011; published online ahead of print at www.jco.org on August 1, 2011

Written on behalf of the Cancer and Aging Research Group.

Supported by Paul Beeson Career Development Award in Aging Research No. K23 AG026749-01 (A.H.), Paul

Beeson Career Development Award No. 1 K08 AG24842 (C.P.G.), and American Society of Clinical Oncology, Association of Specialty Professors, Junior Development Award in Geriatric Oncology (A.H.).

Presented at the 46th Annual Meeting of the American Society of Clinical Oncology, Chicago, IL, June 4-8, 2010

Authors' disclosures of potential conflicts of interest and author contributions are found at the end of this article.

Corresponding author: Arti Hurria, MD City of Hope, 1500 E. Duarte Rd Duarte, CA 91010; e-mail: ahurria @coh.org.

(C) 2011 by American Society of Clinical Oncology

0732-183X/11/2925-3457/\$20.00

DOI: 10.1200/JCO.2011.34.7625

\title{
Predicting Chemotherapy Toxicity in Older Adults With Cancer: A Prospective Multicenter Study
}

Arti Hurria, Kayo Togawa, Supriya G. Mohile, Cynthia Owusu, Heidi D. Klepin, Cary P. Gross, Stuart M. Lichtman, Ajeet Gajra, Smita Bhatia, Vani Katheria, Shira Klapper, Kurt Hansen, Rupal Ramani, Mark Lachs, F. Lennie Wong, and William P. Tew

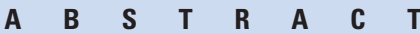

\section{Purpose}

Older adults are vulnerable to chemotherapy toxicity; however, there are limited data to identify those at risk. The goals of this study are to identify risk factors for chemotherapy toxicity in older adults and develop a risk stratification schema for chemotherapy toxicity.

\section{Patients and Methods}

Patients age $\geq 65$ years with cancer from seven institutions completed a prechemotherapy assessment that captured sociodemographics, tumor/treatment variables, laboratory test results, and geriatric assessment variables (function, comorbidity, cognition, psychological state, social activity/support, and nutritional status). Patients were followed through the chemotherapy course to capture grade 3 (severe), grade 4 (life-threatening or disabling), and grade 5 (death) as defined by the National Cancer Institute Common Terminology Criteria for Adverse Events.

\section{Results}

In total, 500 patients with a mean age of 73 years (range, 65 to 91 years) with stage I to IV lung (29\%), GI (27\%), gynecologic (17\%), breast $(11 \%)$, genitourinary $(10 \%)$, or other $(6 \%)$ cancer joined this prospective study. Grade 3 to 5 toxicity occurred in $53 \%$ of the patients (39\% grade 3, $12 \%$ grade $4,2 \%$ grade 5$)$. A predictive model for grade 3 to 5 toxicity was developed that consisted of geriatric assessment variables, laboratory test values, and patient, tumor, and treatment characteristics. A scoring system in which the median risk score was 7 (range, 0 to 19) and risk stratification schema (risk score: percent incidence of grade 3 to 5 toxicity) identified older adults at low (0 to 5 points; 30\%), intermediate (6 to 9 points; $52 \%$ ), or high risk (10 to 19 points; $83 \%)$ of chemotherapy toxicity $(P<.001)$.

\section{Conclusion}

A risk stratification schema can establish the risk of chemotherapy toxicity in older adults. Geriatric assessment variables independently predicted the risk of toxicity.

\section{J Clin Oncol 29:3457-3465. (C) 2011 by American Society of Clinical Oncology}

\section{INTRODUCTION}

Cancer is a disease associated with aging. Patients age 65 years and older have an 11-fold increase in cancer incidence and a 16-fold increase in cancer mortality when compared with those younger than 65 years of age. ${ }^{1}$ This population of older adults is growing rapidly. By 2030, 20\% of the population in the United States will be older than age 65 years. Oncologists are ill prepared for this demographic shift, because older adults have been underrepresented in oncology clinical trials that set the standard of care. ${ }^{2,3}$ The available data suggest that older adults derive benefit from chemotherapy similar to that derived by younger adults, ${ }^{4,5}$ older age is a risk factor for chemotherapy toxicity, ${ }^{6}$ and older adults are less likely to be offered chemotherapy because of con- cerns regarding their ability to tolerate the treatment. ${ }^{7,8}$ Although tools have been developed to quantify chemotherapy benefit by age, ${ }^{9}$ there are no tools to characterize the risks of chemotherapy in older adults.

Currently, there is no consensus within the geriatric or oncology communities regarding a standard assessment that can identify those older adults at risk for chemotherapy toxicity. Existing oncology performance status measures (such as Karnofsky performance status [KPS] ${ }^{10}$ or Eastern Cooperative Oncology Group performance status ${ }^{11}$ ) are applied to all adult patients with cancer regardless of age to estimate functional status, assess eligibility for clinical trials, and predict treatment toxicity and survival. ${ }^{12-14}$ However, these tools were validated in 
younger patients and do not address the heterogeneity in the aging process. Geriatricians perform a geriatric assessment that measures independent clinical predictors of morbidity and mortality in older adults ${ }^{15}$; however, this assessment has not typically been used in daily oncology practice to assist in decision making.

A predictive model that incorporates geriatric and oncologic correlates of vulnerability to chemotherapy toxicity in older adults could help both the healthcare provider and the patient weigh the benefits and risks of chemotherapy treatment and could serve as a platform to test interventions to decrease the risk of chemotherapy toxicity. The primary objective of this prospective longitudinal study was to develop a predictive model for grade 3 to 5 toxicity in a cohort of older adults with cancer that uses age, sociodemographic factors, tumor and treatment characteristics, laboratory data, and geriatric assessment variables. Furthermore, we assessed the predictive capability of this model for chemotherapy toxicity in comparison to KPS, a commonly used oncology performance status measure.

\section{PATIENTS AND METHODS}

The Cancer and Aging Research Group Study "Determining the Utility of an Assessment Tool for Older Adults with Cancer" was open at seven participating institutions. Between November 2006 and November 2009, 500 patients were recruited from the outpatient oncology practices. Eligible patients were age $\geq 65$ years, had a diagnosis of cancer, were scheduled to receive a new chemotherapy regimen, and were fluent in English (since all measures in the geriatric assessment tool were not validated in other languages). Assuming a prevalence rate of $30 \%$ for grade 3 to 5 toxicity, 500 patients would provide $80 \%$ power to detect a prevalence difference of $11 \%$ for a dichotomous predictor in logistic regression. The study was approved by the institutional review board at each participating institution. Participating patients completed the informed consent process.

\section{Study Schema}

Before initiation of the chemotherapy regimen, a geriatric assessment tool was completed. The measures in the tool are outlined in a prior publication describing the development of the tool. ${ }^{16}$ The geriatric assessment tool (Table 1) had a health care provider and a patient portion. The health care provider portion consisted of three items: the patient's KPS, ${ }^{10}$ the Timed Up \& Go measure (a performance-based measure of functional status), ${ }^{22}$ and the Blessed Orientation-Memory-Concentration test ${ }^{23}$ (a screening measure of cognitive function). The patient portion consisted of self-reported measures of functional status, comorbidity, medications, nutrition, psychological state, and social support/function. A member of the health care team assisted those who needed help with completing the questionnaires.

Tumor characteristics (tumor type and stage) and pretreatment laboratory data (WBC count, hemoglobin, blood urea nitrogen, creatinine, albumin, and liver function tests) were recorded. The following treatment characteristics were captured: chemotherapy regimen, line of chemotherapy (first line or greater), the use of WBC or RBC growth factors, and the timing of initiation of WBC growth factors (primary or secondary prophylaxis). The chemotherapy

\begin{tabular}{|c|c|c|c|c|c|c|c|c|}
\hline Domain & Measure & $\begin{array}{l}\text { No. of } \\
\text { Items }\end{array}$ & Description & Range of Scores & Mean & SD & Median & Range \\
\hline \multirow[t]{5}{*}{ Functional status } & $\begin{array}{l}\text { Activities of Daily Living } \\
\text { (subscale of MOS Physical } \\
\text { Health) }{ }^{19}\end{array}$ & 10 & $\begin{array}{l}\text { Measures limitations in a wide range of } \\
\text { physical functions (from } \\
\text { bathing/dressing to vigorous } \\
\text { activities such as running) }\end{array}$ & $\begin{array}{l}\text { 0-100 (higher score: better } \\
\text { physical function) }\end{array}$ & 68.5 & 26 & 75.0 & $0-100$ \\
\hline & $\begin{array}{l}\text { Instrumental Activities of Daily } \\
\text { Living (subscale of the OARS) }{ }^{20}\end{array}$ & 7 & $\begin{array}{l}\text { Measures ability to complete activities } \\
\text { required to maintain independence } \\
\text { in the community (shopping, meal } \\
\text { preparation, making telephone calls, } \\
\text { money management) }\end{array}$ & $\begin{array}{l}\text { 0-14 (higher score: less } \\
\text { need for assistance) }\end{array}$ & 12.9 & 1.8 & 14 & $4-14$ \\
\hline & $\begin{array}{l}\text { Karnofsky Self-Reported } \\
\quad \text { Performance Rating Scale }{ }^{10}\end{array}$ & 1 & $\begin{array}{l}\text { Global indicator of patient function } \\
\text { determined by patient self-report } \\
\text { ranging from "normal" to "severely } \\
\text { disabled" }\end{array}$ & $\begin{array}{l}\text { 40-100 (higher score: } \\
\text { better physical function) }\end{array}$ & 85.6 & 13.7 & 90 & $40-100$ \\
\hline & $\begin{array}{l}\text { Karnofsky Physician-Rated } \\
\text { Performance Rating Scale }\end{array}$ & 1 & $\begin{array}{l}\text { Global indicator of patient function } \\
\text { determined by physician report } \\
\text { ranging from "normal" to "dead" }\end{array}$ & $\begin{array}{l}\text { 0-100 (higher score: better } \\
\text { physical function) }\end{array}$ & 84.7 & 11.4 & 90 & $50-100$ \\
\hline & No. of falls in last 6 months & 1 & $\begin{array}{l}\text { Indicates number of times fallen in the } \\
\text { last } 6 \text { months }\end{array}$ & & 0.3 & 0.8 & 0 & $0-6$ \\
\hline Comorbidity & $\begin{array}{l}\text { Physical Health Section (subscale } \\
\text { of the OARS) }\end{array}$ & & $\begin{array}{l}\text { Presence/absence of } 13 \text { comorbid } \\
\text { illnesses: Number of comorbid } \\
\text { illnesses }\end{array}$ & & 2.5 & 1.7 & 2 & $0-9$ \\
\hline Psychological state & $\begin{array}{l}\text { Hospital Anxiety and Depression } \\
\text { Scale }^{20 a}\end{array}$ & 14 & $\begin{array}{l}\text { Assesses the level of depression and } \\
\text { anxiety experienced in the past } \\
\text { week }\end{array}$ & $\begin{array}{l}\text { 0-100 (higher score: poorer } \\
\text { psychological state) }\end{array}$ & 8.3 & 6.0 & 7 & $0-35$ \\
\hline Social activity & MOS Social Activity Survey ${ }^{19}$ & 4 & $\begin{array}{l}\text { Measures the degree in which physical } \\
\text { or emotional problems interfere with } \\
\text { level of social activity }\end{array}$ & $\begin{array}{l}\text { 0-100 (higher score: better } \\
\text { social activity) }\end{array}$ & 56.2 & 22.8 & 58.3 & $0-100$ \\
\hline Social support & $\begin{array}{l}\text { MOS Social Support Survey: } \\
\text { Emotional/Information and } \\
\text { Tangible Subscales } \\
21 a\end{array}$ & 12 & $\begin{array}{l}\text { Measures the perceived availability of } \\
\text { social support }\end{array}$ & $\begin{array}{l}\text { 0-100 (higher score: better } \\
\text { social support) }\end{array}$ & 84.9 & 21.3 & 95.8 & $0-100$ \\
\hline \multirow[t]{2}{*}{ Nutrition } & Body mass index & 1 & Weight in $\mathrm{kg} /(\text { height in } \mathrm{m})^{2}$ & & 26.2 & 4.7 & 25.0 & $14.9-52.2$ \\
\hline & $\begin{array}{l}\text { Percent unintentional weight loss } \\
\text { in last } 6 \text { months }\end{array}$ & 1 & $\begin{array}{l}\text { (Unintentional weight lost in last } 6 \\
\text { months/baseline body weight) } \times \\
100\end{array}$ & & 4.7 & 6.2 & 2.0 & $0-32.3$ \\
\hline
\end{tabular}

Abbreviations: MOS, Medical Outcomes Study; OARS, Older American Resources and Services; SD, standard deviation. 
dosing for the first cycle of treatment was categorized as standard or dose reduced per the National Comprehensive Cancer Network guidelines. ${ }^{24}$

The patient was followed from beginning until the end of the chemotherapy course. Toxicities were captured at each clinical encounter (scheduled or emergency visits). Two physicians (the national study principal investigator and site principal investigator) reviewed the patient's chemotherapy course to capture grade 3 to 5 chemotherapy-related toxicities (grade 3 , severe; grade 4 , life-threatening; and grade 5, fatal) by using the National Cancer Institute Common Terminology Criteria for Adverse Events (NCI CTCAE), version 3.0. ${ }^{25}$ Blood values were captured as grade 3 to 5 toxicity if they met the criteria on the date of scheduled chemotherapy or at the time the patient was seeking attention because of chemotherapy toxicities.

\section{Statistical Analyses}

Descriptive analyses were performed to summarize patient, tumor, and treatment characteristics and geriatric assessment results. The incidence of the specific categories (hematologic and nonhematologic) and types of NCI CTCAE grade 3,4 , or 5 toxicity were calculated.

Model development. A predictive model for chemotherapy toxicity was developed. The $\chi^{2}$ test was used to examine the association between grade 3 to 5 toxicity and the following variables: sociodemographic factors (age, sex, education, marital status, household composition, employment status, race/ ethnicity), study site, cancer type (breast, GI, genitourinary [GU], gynecologic [GYN], lung, and other), cancer stage, chemotherapy dosing (standard or dose reduced), number of chemotherapy drugs (mono- or polychemotherapy), line of treatment (first line or greater), chemotherapy duration, receipt of primary prophylaxis with WBC growth factor, prechemotherapy laboratory values (WBC, hemoglobin, liver function tests, albumin, creatinine clearance [calculated by the Cockgroft and Gault, ${ }^{26}$ Jeliffe, ${ }^{27}$ Modification of Diet in Renal Disease, ${ }^{28}$ and Wright ${ }^{29}$ formulas]), and responses to the items in the Geriatric Assessment measures (Table 1).

For numerical variables, the Youden Index ${ }^{30}$ was used to identify the cut point with the highest sensitivity and specificity in classifying the presence or absence of toxicity. The variables that reached a $P$ value of less than .1 and clinically relevant variables (chemotherapy dosing [standard or dose reduced], number of drugs [mono- or polychemotherapy], chemotherapy duration, and receipt of primary prophylaxis with WBC growth factor) were further examined in a multivariate logistic regression model by using the best subset method ${ }^{31}$ to identify the best combined sets of risk factors that best predicted chemotherapy toxicity. We evaluated the discrimination of those models by calculating the area under the receiver operation characteristic (ROC) curve and goodness-of-fit by using the Hosmer-Lemeshow test. ${ }^{32}$ Interactions among the selected risk factors were evaluated by introducing interaction terms to the model one at a time.

Developing the scoring system. A risk score for each risk factor was calculated by dividing the $\beta$ coefficient of the variable by the lowest $\beta$ coefficient in the model, rounded to the nearest whole number. ${ }^{33,34}$ The sum of the scores for each patient was calculated. The sample was divided into three risk strata (low, medium, and high risk) on the basis of approximate quartiles of risk score with the middle two quartiles combined. The difference in toxicity incidence among the strata was evaluated by using the $\chi^{2}$ test. The discrimination and calibration of the predictive model were assessed by using the total score as a predictor of chemotherapy toxicity.

Internal validation. The model was internally validated by using the 10 -fold cross-validation process. ${ }^{35,36}$ The study sample was randomly partitioned into 10 groups, by using nine-tenths of the cohort to obtain the $\beta$ coefficient and then applying the $\beta$ coefficient to examine the area under the ROC curve in the tenth group. This process was repeated 10 times to obtain the average area under the ROC curve of the model. All statistical analyses were performed by using SAS 9.1 (SAS Institute, Cary, NC).

\section{RESULTS}

\section{Patient, Tumor, and Treatment Characteristics}

The study cohort consisted of 500 patients age $\geq 65$ years with stage I to IV cancer (Table 2). The mean age of participants was 73

\begin{tabular}{|c|c|c|}
\hline Characteristic & $\begin{array}{c}\text { No. of } \\
\text { Patients }\end{array}$ & $\%$ Patients \\
\hline \multicolumn{3}{|l|}{ Age, years } \\
\hline $65-69$ & 175 & 35 \\
\hline $70-74$ & 127 & 25 \\
\hline $75-79$ & 105 & 21 \\
\hline $80-84$ & 73 & 15 \\
\hline $85-91$ & 20 & 4 \\
\hline \multicolumn{3}{|l|}{ Sex } \\
\hline Female & 281 & 56 \\
\hline Male & 219 & 44 \\
\hline \multicolumn{3}{|l|}{ Cancer type } \\
\hline Breast & 57 & 11 \\
\hline Lung & 143 & 29 \\
\hline GI & 135 & 27 \\
\hline GYN & 87 & 17 \\
\hline GU & 50 & 10 \\
\hline Other & 28 & 6 \\
\hline \multicolumn{3}{|l|}{ Cancer stage } \\
\hline I & 23 & 5 \\
\hline ॥ & 59 & 12 \\
\hline III & 109 & 22 \\
\hline Limited & 2 & 0 \\
\hline IV/extensive & 307 & 61 \\
\hline \multicolumn{3}{|l|}{ Educational level } \\
\hline Less than high school & 18 & 4 \\
\hline High school graduate & 175 & 35 \\
\hline Associate/bachelor's degree & 202 & 40 \\
\hline Advanced degree & 104 & 21 \\
\hline Missing & 1 & 0 \\
\hline \multicolumn{3}{|l|}{ Marital status } \\
\hline Married & 306 & 61 \\
\hline Widowed & 113 & 23 \\
\hline Single & 16 & 3 \\
\hline Separated, divorced & 65 & 13 \\
\hline \multicolumn{3}{|l|}{ Employment status } \\
\hline Full or part-time & 83 & 17 \\
\hline Retired, homemaker, unemployed & 395 & 79 \\
\hline Disabled, medical leave & 21 & 4 \\
\hline Missing & 1 & 0 \\
\hline \multicolumn{3}{|l|}{ Household composition } \\
\hline Lives alone & 106 & 21 \\
\hline Lives with spouse, partner, or child & 390 & 78 \\
\hline Missing & 4 & 1 \\
\hline \multicolumn{3}{|l|}{ Race/ethnicity } \\
\hline White & 426 & 85 \\
\hline Black & 42 & 8 \\
\hline Asian & 26 & 5 \\
\hline Other & 6 & 1 \\
\hline
\end{tabular}

Abbreviations: GU, genitourinary; GYN, gynecologic.

years (standard deviation [SD], 6.2; range, 65 to 91 years) with stage I (5\%), II (12\%), III (22\%), and IV (61\%) cancer. The most common tumor types were lung (29\%), GI (27\%), GYN (17\%), and breast (11\%). Seventy percent received polychemotherapy, $76 \%$ received standard doses of chemotherapy, 71\% received first-line treatment, and $18 \%$ received primary prophylaxis with WBC growth factors.

\section{Geriatric Assessment Results}

The mean score on the instrumental activities of daily living scale was 12.9 (SD, 1.8 ; range, 4 to 14 ), with $43 \%$ of patients requiring 
assistance with those activities. The mean score on the Medical Outcomes Study (MOS) Physical Health Scale was 68.5 (SD, 26; range 0 to 100 ), with a score of 0 indicating completely dependent and a score of 100 indicating full physical capacity. The patients' KPS ranged from $40 \%$ to $100 \%$ with $79 \%$ of patients with a status greater than $70 \%$. Eighteen percent reported at least one fall in the last 6 months, and $90 \%$ had at least one comorbid condition. The most common comorbid conditions were hypertension (52\%), arthritis (46\%), heart disease (20\%), and stomach disorders (19\%). Twelve percent had a low body mass index of less than 22 , and $18 \%$ were obese (body mass index $>30$ ). Thirty-eight percent reported unintentional weight loss of more than $5 \%$ of body weight over the past 6 months (Table 1 ).

\section{Chemotherapy Toxicity}

At least one grade 3 to 5 toxicity occurred in $53 \%$ of patients (39\% grade $3,12 \%$ grade 4 , and $2 \%$ grade 5 [percentages reflect the worst grade of toxicity experienced]; Table 3). Grade 3 to 5 hematologic and nonhematologic toxicity occurred in $26 \%$ and $43 \%$, respectively. The most common grade 3 to 5 hematologic toxicities were neutropenia (11\%), leucopenia (10\%), and anemia (10\%). The most common grade 3 to 5 nonhematologic toxicities were fatigue (16\%), infection (10\%), and dehydration (9\%). Thirty-one percent of patients required a dose reduction during therapy, $31 \%$ had a dose delay, and $23 \%$ were hospitalized during treatment.

\begin{tabular}{|c|c|c|c|c|c|c|c|c|}
\hline \multirow[b]{2}{*}{ Toxicity Type } & \multicolumn{2}{|c|}{$\begin{array}{c}\text { Grade } 3 \\
\text { to } 5 \\
\end{array}$} & \multicolumn{2}{|c|}{ Grade 3} & \multicolumn{2}{|c|}{ Grade 4} & \multicolumn{2}{|c|}{$\begin{array}{c}\text { Grade } \\
5^{*}\end{array}$} \\
\hline & No. & $\%$ & No. & $\%$ & No. & $\%$ & No. & $\%$ \\
\hline Hematologic and nonhematologic $†$ & 265 & 53 & 197 & 39 & 58 & 12 & 10 & 2 \\
\hline Hematologic & 131 & 26 & 90 & 18 & 39 & 8 & 2 & 0 \\
\hline ANC & 57 & 11 & 40 & 8 & 17 & 3 & 0 & 0 \\
\hline WBC & 49 & 10 & 41 & 8 & 8 & 2 & 0 & 0 \\
\hline Hemoglobin & 48 & 10 & 45 & 9 & 3 & 1 & 0 & 0 \\
\hline Platelets & 25 & 5 & 14 & 3 & 11 & 2 & 0 & 0 \\
\hline Infection with abnormal ANC & 10 & 2 & 7 & 1 & 1 & 0 & 2 & 0 \\
\hline Nonhematologic & 217 & 43 & 184 & 37 & 25 & 5 & 8 & 2 \\
\hline Fatigue & 81 & 16 & 79 & 16 & 2 & 0 & 0 & 0 \\
\hline Infection with normal ANC & 48 & 10 & 40 & 8 & 5 & 1 & 3 & $1 \neq$ \\
\hline Dehydration & 43 & 9 & 41 & 8 & 2 & 0 & 0 & 0 \\
\hline Thrombosis/embolism & 22 & 4 & 17 & 3 & 4 & 1 & 1 & $0 \ddagger$ \\
\hline Hyponatremia & 22 & 4 & 22 & 4 & 0 & 0 & 0 & 0 \\
\hline Diarrhea & 22 & 4 & 19 & 4 & 3 & 1 & 0 & 0 \\
\hline Hypokalemia & 15 & 3 & 15 & 3 & 0 & 0 & 0 & 0 \\
\hline Dyspnea & 13 & 3 & 5 & 1 & 7 & 1 & 1 & 0 \\
\hline Syncope & 13 & 3 & 13 & 3 & 0 & 0 & 0 & 0 \\
\hline Neuropathy & 13 & 3 & 13 & 3 & 0 & 0 & 0 & 0 \\
\hline Nausea & 12 & 2 & 12 & 2 & 0 & 0 & 0 & 0 \\
\hline \multicolumn{9}{|c|}{$\begin{array}{l}\text { Abbreviation: ANC, absolute neutrophil count. } \\
\text { *Additional causes of grade } 5 \text { toxicities include cardiac ischemia/infarction, } \\
\text { liver dysfunction/failure, pneumonitis/pulmonary infiltrate, and sudden death. } \\
\text { †The percentages for grades } 3 \text { to } 5 \text { toxicity reflect the worst grade of toxicity } \\
\text { experienced by the individual. Since patients could have both hematologic and } \\
\text { nonhematologic toxicity, the sum of hematologic and nonhematologic toxici- } \\
\text { ties is greater than the number of all types of toxicity. } \\
\text { fOne patient had grade } 5 \text { infection with normal ANC and grade } 5 \text { thrombosis/ } \\
\text { embolism. Another patient had grade } 5 \text { infection with normal ANC and grade } \\
5 \text { metabolic encephalopathy. }\end{array}$} \\
\hline
\end{tabular}

\section{Factors Associated With Increased Risk of Chemotherapy Toxicity}

The risk factors (Table 4 ) associated with grade 3 to 5 toxicity in univariate analysis $(P<.1)$ and variables deemed to be of clinical importance (chemotherapy dosing [standard or dose reduced], number of chemotherapy drugs [mono- or polychemotherapy], and primary prophylaxis with WBC growth factor) were used to derive the model for chemotherapy toxicity which includes the following risk factors:

age $\geq 72$ years, cancer type (GI or GU), standard dosing of chemotherapy, polychemotherapy, hemoglobin (males: $<11 \mathrm{~g} / \mathrm{dL}$; females: $<10$ $\mathrm{g} / \mathrm{dL}$ ), creatinine clearance less than $34 \mathrm{~mL} / \mathrm{min}$ (Jelliffe formula ${ }^{27}$ using ideal weight), hearing impairment described as fair or worse, $\geq$ one fall in the last 6 months, limited in walking one block, need for assistance in taking medications, and decreased social activities because of physical or emotional health. No significant interaction among the selected variables was found. Both the model of 11 risk factors and the model of total risk score achieved good calibration (Hosmer-Lemeshow test, $P=.85$ and $P=.25$, respectively) and discrimination (both models: $\mathrm{ROC}=0.72$; Tables 5 and 6 ).

Risk scores were assigned to each risk factor, as described in the Statistical Analyses section (Table 5). The median overall risk score was 7 (range, 0 to 19). The cohort was divided into three categories on the basis of the risk of grade 3 to 5 toxicity: low risk ( 0 to 5 points, $30 \%$ ), intermediate risk ( 6 to 9 points, $52 \%$ ), and high risk (10 to 19 points, $83 \%)$. There was a significant difference in toxicity among the risk groups $(P<.001$; Fig 1 and Table 6$)$.

Exploratory analyses were performed to calculate the ROC of the model by using the total risk score for each tumor type: GI (0.72), GU (0.76), breast (0.66), lung (0.68), GYN (0.66), and other (0.81) cancers.

\section{Ability of the Model to Predict Toxicity in Comparison With KPS}

The association between KPS and chemotherapy toxicity is described in Figure 1 and Table 6. There was no significant difference in the incidence of toxicity across the KPS-based risk groups $(P=.19)$. The ROC of the model with KPS (as a continuous variable) was 0.53 which was lower than the ROC of the risk score model, 0.72 . Furthermore, the addition of KPS to our final model did not improve the ROC.

\section{Internal Validation of the Predictive Model}

A 10-fold cross validation yielded an area under the curve statistic of 0.72 , indicating that the model retained a good discrimination.

\section{DISCUSSION}

This prospective multicenter study demonstrated that chemotherapy toxicity is common in older adults, with $53 \%$ experiencing at least one grade 3 to 5 toxicity. Among these, 2\% experienced a treatmentrelated mortality. A predictive model was developed to identify those patients at greatest risk, including factors obtained in everyday practice (patient age, number of chemotherapy drugs, dosing, and laboratory values) and factors not typically used in everyday oncology practice (geriatric assessment variables). This model had a greater 


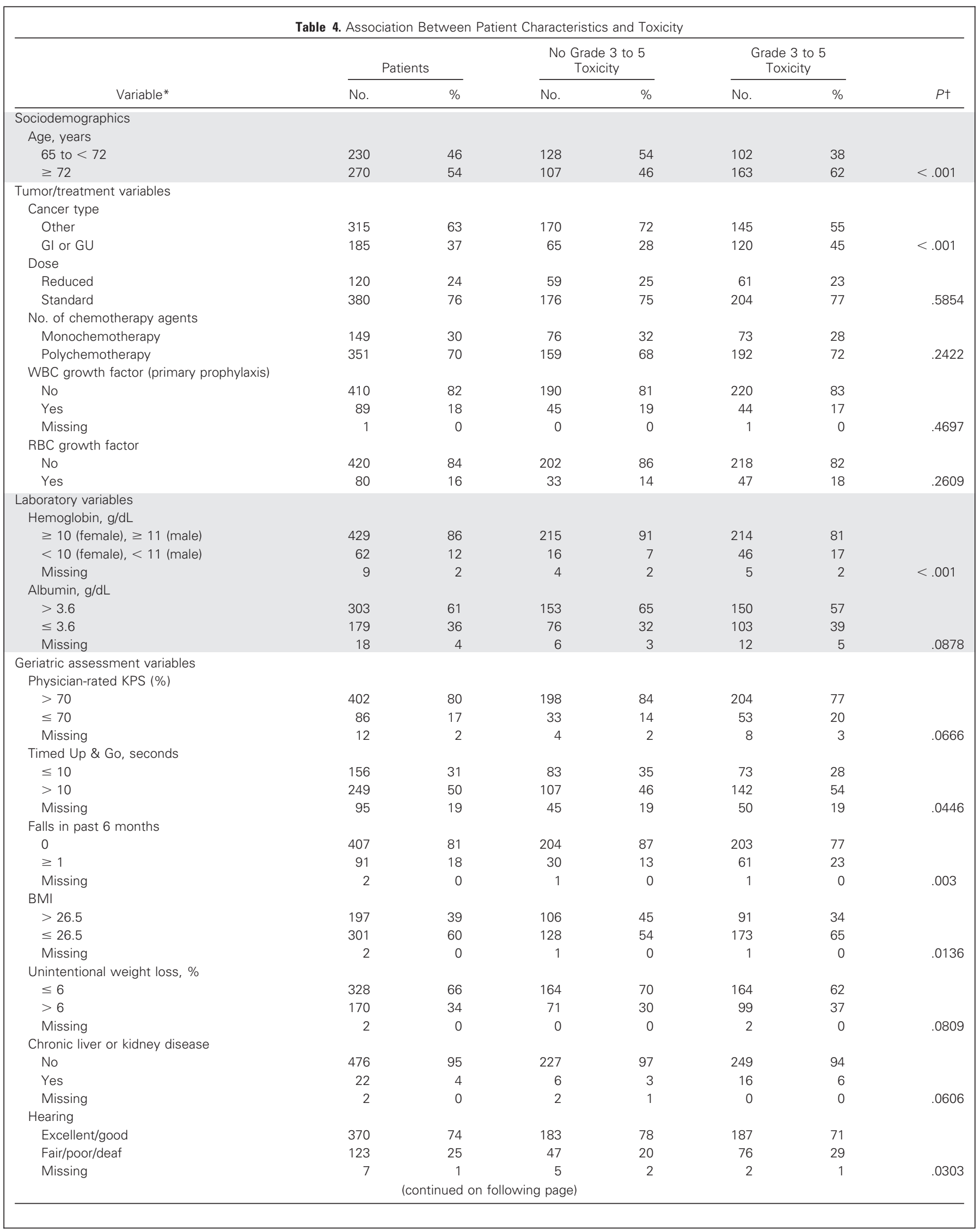




\begin{tabular}{|c|c|c|c|c|c|c|c|}
\hline \multicolumn{8}{|l|}{ Mobility } \\
\hline No assistance & 411 & 82 & 204 & 87 & 207 & 78 & \\
\hline Requires assistance & 89 & 18 & 31 & 13 & 58 & 22 & .0112 \\
\hline Requires assistance & 178 & 36 & 72 & 31 & 106 & 40 & \\
\hline Missing & 2 & 0 & 1 & 0 & 1 & 0 & .0292 \\
\hline \multicolumn{8}{|l|}{ Medication intake } \\
\hline No assistance & 461 & 92 & 224 & 95 & 237 & 89 & \\
\hline Requires assistance & 39 & 8 & 11 & 5 & 28 & 11 & .0143 \\
\hline \multicolumn{8}{|l|}{ Moderate activities } \\
\hline Not limited at all & 253 & 51 & 135 & 57 & 118 & 45 & \\
\hline Limited & 244 & 49 & 100 & 43 & 144 & 54 & \\
\hline Missing & 3 & 1 & 0 & 0 & 3 & 1 & .0057 \\
\hline \multicolumn{8}{|l|}{ Limited in walking several blocks } \\
\hline Not limited at all & 286 & 57 & 146 & 62 & 140 & 53 & \\
\hline Limited & 208 & 42 & 85 & 36 & 123 & 46 & \\
\hline Missing & 6 & 1 & 4 & 2 & 2 & 1 & .0251 \\
\hline \multicolumn{8}{|l|}{ Limited in walking one block } \\
\hline Not limited at all & 386 & 77 & 192 & 82 & 194 & 73 & \\
\hline Limited & 109 & 22 & 40 & 17 & 69 & 26 & \\
\hline Missing & 5 & 1 & 3 & 1 & 2 & 1 & .016 \\
\hline Missing & 4 & 1 & 1 & 0 & 3 & 1 & .0493 \\
\hline \multicolumn{8}{|l|}{$\begin{array}{l}\text { Limited social activity compared with others } \\
\text { your age }\end{array}$} \\
\hline $\begin{array}{l}\text { About the same, somewhat, or much less } \\
\text { limited than others }\end{array}$ & 334 & 67 & 167 & 71 & 167 & 63 & \\
\hline Somewhat, or much more limited than others & 160 & 32 & 66 & 28 & 94 & 35 & \\
\hline Missing & 6 & 1 & 2 & 1 & 4 & 2 & .0683 \\
\hline $\begin{array}{l}\text { Abbreviations: BMI, body mass index; GU, genitour } \\
\text { For numerical variables, the Youden Inde }{ }^{30} \text { was ex } \\
\text { e presence or absence of toxicity. The variables th } \\
\text { duced], number of chemotherapy drugs in the reg } \\
\text { xamined in a multivariate logistic regression model } \\
+\chi^{2} \text { test was conducted for observations without } n\end{array}$ & $\begin{array}{l}\text { Karn } \\
\text { deter } \\
\text { d a } P \\
\text { o- or } \\
\text { ues. }\end{array}$ & other & $\begin{array}{l}\text { Is. } \\
\text { respor } \\
\text { clinica } \\
\text { receip }\end{array}$ & $\begin{array}{l}\text { nad th } \\
\text { nt va } \\
\text { ry pr }\end{array}$ & $\begin{array}{l}\text { sensi } \\
\text { hemot } \\
\text { with V }\end{array}$ & $\begin{array}{l}\text { speci } \\
\text { sing } \\
\text { th fa }\end{array}$ & $\begin{array}{l}\text { ssifying } \\
\text { or dose } \\
\text { further }\end{array}$ \\
\hline
\end{tabular}

ability to discriminate risk of chemotherapy toxicity than the KPS, which is commonly used in oncology practice.

Older adults are at increased risk for chemotherapy toxicity; however, oncologists are left with little guidance when it comes to identifying risk factors other than chronologic age. It is generally recognized that chronologic age does not equate to physiologic age. Geriatricians perform a geriatric assessment to identify clinical predictors of morbidity and mortality ${ }^{15}$; however, this assessment has not been routinely incorporated into oncology care because of the time and resource requirements. Furthermore, there is a lack of guidelines regarding how to interpret the findings in the context of oncology care.

The predictive model identified patient age, tumor, treatment, laboratory values, and geriatric assessment variables as risk factors for chemotherapy toxicity. There is a rational explanation for why each of these factors may predict chemotherapy toxicity. Although older age is associated with an accumulation of physiologic deficit, there is controversy about which chronologic age defines an individual as "older." Age $\geq 72$ years as a risk factor for chemotherapy toxicity provides 


\begin{tabular}{|c|c|c|c|c|c|c|c|}
\hline \multirow[b]{3}{*}{ Risk Factor } & \multicolumn{7}{|c|}{ ble 5. Predictive Model } \\
\hline & \multicolumn{2}{|c|}{ Prevalence } & \multicolumn{2}{|c|}{$\begin{array}{l}\text { Grades } \\
3 \text { to } 5 \\
\text { Toxicity } \\
\end{array}$} & \multirow[b]{2}{*}{ OR } & \multirow[b]{2}{*}{$95 \% \mathrm{Cl}$} & \multirow[b]{2}{*}{ Score } \\
\hline & No. & $\%$ & No. & $\%$ & & & \\
\hline Age $\geq 72$ years & 270 & 54 & 163 & 60 & 1.85 & 1.22 to 2.82 & 2 \\
\hline Cancer type GI or GU & 185 & 37 & 120 & 65 & 2.13 & 1.39 to 3.24 & 2 \\
\hline $\begin{array}{l}\text { Chemotherapy dosing, } \\
\text { standard dose }\end{array}$ & 380 & 76 & 204 & 54 & 2.13 & 1.29 to 3.52 & 2 \\
\hline $\begin{array}{l}\text { No. of chemotherapy drugs, } \\
\text { polychemotherapy }\end{array}$ & 351 & 70 & 192 & 55 & 1.69 & 1.08 to 2.65 & 2 \\
\hline $\begin{array}{l}\text { Hemoglobin }<11 \mathrm{~g} / \mathrm{dL} \\
\text { (male), }<10 \mathrm{~g} / \mathrm{dL} \\
\text { (female) }\end{array}$ & 62 & 12 & 46 & 74 & 2.31 & 1.15 to 4.64 & 3 \\
\hline $\begin{array}{l}\text { Creatinine clearance } \\
\text { (Jelliffe, ideal weight) } \\
<34 \mathrm{~mL} / \mathrm{min}\end{array}$ & 44 & 9 & 34 & 772 & 2.46 & 1.11 to 5.44 & 3 \\
\hline Hearing, fair or worse & 123 & 25 & 76 & 62 & 1.67 & 1.04 to 2.69 & 2 \\
\hline $\begin{array}{l}\text { No. of falls in last } 6 \\
\text { months, } 1 \text { or more }\end{array}$ & 91 & 18 & 61 & 67 & 2.47 & 1.43 to 4.27 & 3 \\
\hline $\begin{array}{l}\text { IADL: Taking medications, } \\
\text { with some help/unable }\end{array}$ & 39 & 8 & 28 & 72 & 1.50 & 0.66 to 3.38 & 1 \\
\hline $\begin{array}{l}\text { MOS: Walking } 1 \text { block, } \\
\text { somewhat } \\
\text { limited/limited a lot }\end{array}$ & 109 & 22 & 69 & 63 & 1.71 & 1.02 to 2.86 & 2 \\
\hline $\begin{array}{l}\text { MOS: Decreased social } \\
\text { activity because of } \\
\text { physical/emotional } \\
\text { health, limited at least } \\
\text { sometimes }\end{array}$ & 218 & 44 & 126 & 58 & 1.36 & 0.90 to 2.06 & 1 \\
\hline
\end{tabular}

evidence for the seventh decade of life as a time when the cumulative effects of aging are associated with increased vulnerability.

Tumor and treatment variables were identified as risk factors for chemotherapy toxicity. Patients with GI and GU cancers were at increased risk for toxicity, possibly reflective of the type of chemotherapy delivered or alterations in physiology (diarrhea/ impaired fluid balance) associated with the cancer or the treatment. Receipt of polychemotherapy and/or standard dosing of chemotherapy were associated with an increased risk of toxicity. Aging is associated with decreased bone marrow reserve and an increased risk of myelosuppressive-associated complications from chemotherapy. ${ }^{37,38}$ The receipt of polychemotherapy further increases the risk of myelosuppressive effects from chemotherapy
Table 6. Ability of Risk Score Versus Physician-Rated KPS to Predict Chemotherapy Toxicity

\begin{tabular}{|c|c|c|c|c|c|c|c|}
\hline \multirow[b]{2}{*}{ Risk Strata } & \multicolumn{2}{|c|}{$\begin{array}{c}\text { No } \\
\text { Toxicity }\end{array}$} & \multicolumn{2}{|c|}{ Toxicity } & \multirow[b]{2}{*}{ Total } & \multirow[b]{2}{*}{$P$} & \multirow[b]{2}{*}{$\mathrm{ROC}$} \\
\hline & No. & $\%$ & No. & $\%$ & & & \\
\hline By total score & & & & & & $<.001$ & $0.72^{*}$ \\
\hline $0-5$ (low) & 89 & 70 & 39 & 30 & 128 & & \\
\hline $6-9$ (mid) & 110 & 48 & 117 & 52 & 227 & & \\
\hline 10-19 (high) & 19 & 17 & 90 & 83 & 109 & & \\
\hline By physician-rated KPS (\%) & & & & & & .19 & $0.53^{*}$ \\
\hline $90-100$ & 125 & 49 & 128 & 51 & 253 & & \\
\hline 80 & 73 & 49 & 76 & 51 & 149 & & \\
\hline$\leq 70$ & 33 & 38 & 53 & 62 & 86 & & \\
\hline
\end{tabular}

Abbreviations: KPS, Karnofsky performance status; ROC, receiver operating characteristic.

${ }^{*}$ Risk score and physician-rated KPS were treated as continuous to calculate the ROC.

and can potentially amplify the physiologic stress of a regimen secondary to overlapping toxicities.

Laboratory values (anemia and renal dysfunction) were identified as risk factors for chemotherapy toxicity. The presence of anemia can further increase susceptibility to myelosuppression with certain antineoplastic drugs that are heavily bound to RBCs (epipodophyllotoxins, anthracyclines, camptothecins) by increasing the volume of distribution of these drugs. ${ }^{39}$ In the geriatric population, anemia is an independent predictor of hospitalization and mortality, perhaps representing a global measure of decreased reserve. ${ }^{40}$ There is an age-related decrease in renal function which could impact the pharmacokinetics of renally metabolized drugs. ${ }^{17}$

Geriatric assessment variables were a critical part of the predictive model. Among geriatric patients, functional status is a strong predictor of morbidity and mortality. ${ }^{18}$ Four questions that reflected the patient's functional status were included in the model (ability to walk one block, decreased social activities because of physical or emotional problems, falls in the last 6 months, and the need for assistance with taking medications). The need for assistance with taking medications could also be a surrogate measure of cognitive function, grip strength (unable to open the bottle), or vision (unable to see the instructions). A decrease in social activities because of physicalor emotional problems may represent both a functional measure and a measure of psychological state. Finally, poor hearing was identified
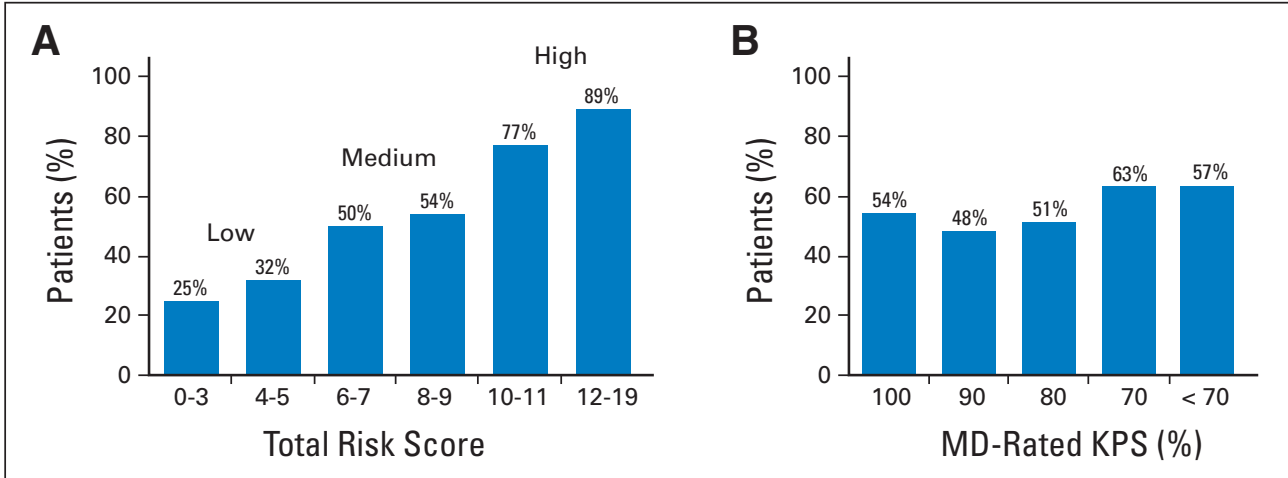

Fig 1. Ability of $(A)$ risk score versus (B) physician-rated Karnofsky performance status (KPS) to predict chemotherapy toxicity. Graphs show grade 3 to 5 toxicity. 
as a risk factor for chemotherapy toxicity, potentially reflecting whether the patient could hear the instructions regarding potentialadverse effects, supportive care medications, and indications of when to seek medical attention.

These findings contribute to an ongoing paradigm shift in oncology assessment. The commonly used oncology performance status measure (KPS) did not identify older adults at increased risk for chemotherapy toxicity, reflecting the limitations of trying to use one global assessment measure of functional status to describe the heterogeneity in the geriatric population. Furthermore, the KPS might be misleading. In older adults it is difficult to discriminate between a KPS of $80 \%$ ("normal activity with effort; some signs or symptoms of disease") and KPS of $60 \%$ ("requires occasional assistance, but is able to care for most of his/her needs").

There are limitations to this study. This study reported on grade 3 to 5 toxicity; however, some grade 2 toxicities (diarrhea, neuropathy) may also be relevant to the geriatric population. Our study population was heterogeneous, consisting of patients with different tumor types and treatment regimens. Our rationale behind studying a heterogeneous population was to determine whether there are common factors that are predictive of vulnerability in the geriatric oncology population; however, there may be additional or different risk factors that are predictive of toxicity based on tumor type or treatment regimen. Exploratory analyses revealed that the ROC of the model was similar when applied to the different tumor types; however, our future research will focus on refining the model among patients with specific tumor types who are receiving specific treatment regimens. Finally, although the model was internally validated, these findings need to be validated externally in an independent cohort.

This study fills critical gaps in the knowledge of predictors for chemotherapy toxicity in older adults, something that does not currently exist and for which there is an enormous and growing need. It unites the fields of geriatrics and oncology by incorporating geriatric correlates of vulnerability, studying their impact in a diverse population of older adults with cancer, and identifying common risk factors for chemotherapy toxicity. Ultimately, these data will provide the basis for future intervention studies aimed at decreasing the risk of chemotherapy toxicity and maintaining the function and health of older adults with cancer.

\section{AUTHORS' DISCLOSURES OF POTENTIAL CONFLICTS OF INTEREST}

Although all authors completed the disclosure declaration, the following author $(s)$ indicated a financial or other interest that is relevant to the subject matter under consideration in this article. Certain relationships marked with a "U" are those for which no compensation was received; those relationships marked with a "C" were compensated. For a detailed description of the disclosure categories, or for more information about ASCO's conflict of interest policy, please refer to the Author Disclosure Declaration and the Disclosures of Potential Conflicts of Interest section in Information for Contributors.

Employment or Leadership Position: None Consultant or Advisory Role: Arti Hurria, Amgen (C), Genentech (C), GTx (C) Stock Ownership: None Honoraria: None Research Funding: Arti Hurria, Abraxis BioScience (Celgene), GlaxoSmithKline Expert Testimony: None Other Remuneration: None

\section{AUTHOR CONTRIBUTIONS}

Conception and design: Arti Hurria, Mark Lachs

Financial support: Arti Hurria

Administrative support: Arti Hurria

Provision of study materials or patients: Arti Hurria, Supriya G.

Mohile, Cynthia Owusu, Heidi D. Klepin, Cary P. Gross, Stuart M.

Lichtman, Ajeet Gajra, William P. Tew

Collection and assembly of data: Arti Hurria, Kayo Togawa, Supriya G.

Mohile, Cynthia Owusu, Heidi D. Klepin, Cary P. Gross, Stuart M.

Lichtman, Ajeet Gajra, Vani Katheria, Shira Klapper, Kurt Hansen, Rupal Ramani, William P. Tew

Data analysis and interpretation: Arti Hurria, Kayo Togawa, Supriya G. Mohile, Cynthia Owusu, Heidi D. Klepin, Cary P. Gross, Stuart M. Lichtman, Ajeet Gajra, Smita Bhatia, F. Lennie Wong, William P. Tew Manuscript writing: All authors

Final approval of manuscript: All authors

\section{REFERENCES}

1. Smith BD, Smith GL, Hurria A, et al: Future of cancer incidence in the United States: Burdens upon an aging, changing nation. J Clin Oncol 27:27582765, 2009

2. Hutchins LF, Unger JM, Crowley JJ, et al: Underrepresentation of patients 65 years of age or older in cancer-treatment trials. N Engl J Med 341: 2061-2067, 1999

3. Talarico L, Chen G, Pazdur R: Enrollment of elderly patients in clinical trials for cancer drug registration: A 7-year experience by the US Food and Drug Administration. J Clin Oncol 22:46264631, 2004

4. Muss HB, Woolf S, Berry D, et al: Adjuvant chemotherapy in older and younger women with lymph node-positive breast cancer. JAMA 293: 1073-1081, 2005

5. Sargent DJ, Goldberg RM, Jacobson SD, et al: A pooled analysis of adjuvant chemotherapy for resected colon cancer in elderly patients. N Eng J Med 345:1091-1097, 2001

6. Muss HB, Berry DA, Cirrincione $C$, et al: Toxicity of older and younger patients treated with adjuvant chemotherapy for node-positive breast cancer: The Cancer and Leukemia Group B Experience. J Clin Oncol 25:3699-3704, 2007

7. Hurria $A$, Wong $F L$, Villaluna $D$, et al: Role of age and health in treatment recommendations for older adults with breast cancer: The perspective of oncologists and primary care providers. J Clin Oncol 26:5386-5392, 2008

8. Kornblith $A B$, Kemeny $M$, Peterson $B L$, et al: Survey of oncologists' perceptions of barriers to accrual of older patients with breast carcinoma to clinical trials. Cancer 95:989-996, 2002

9. Ravdin PM, Siminoff LA, Davis GJ, et al: Computer program to assist in making decisions about adjuvant therapy for women with early breast cancer. J Clin Oncol 19:980-991, 2001

10. Karnofsky DA, Burchenal JH: The clinical evaluation of chemotherapeutic agents in cancer, in Macleod CM (ed): Evaluation of Chemotherapeutic Agents. New York, NY, Columbia University Press, 1948, pp 191-205

11. Zubrod C, Schneiderman M, Frei E III, et al: Appraisal of methods for the study of chemotherapy of cancer in man: Comparative therapeutic trial of nitrogen mustard and triethylene thiophosphoramide. J Chron Dis 11:7-33, 1960
12. Bajorin DF, Dodd PM, Mazumdar M, et al: Long-term survival in metastatic transitional-cell carcinoma and prognostic factors predicting outcome of therapy. J Clin Oncol 17:3173-3181, 1999

13. Motzer RJ, Bacik J, Schwartz LH, et al: Prognostic factors for survival in previously treated patients with metastatic renal cell carcinoma. J Clin Oncol 22:454-463, 2004

14. Albain KS, Crowley JJ, LeBlanc M, et al: Survival determinants in extensive-stage non-smallcell lung cancer: The Southwest Oncology Group experience. J Clin Oncol 9:1618-1626, 1991

15. Extermann M, Hurria A: Comprehensive geriatric assessment for older patients with cancer. J Clin Oncol 25:1824-1831, 2007

16. Hurria A, Gupta S, Zauderer M, et al: Developing a cancer-specific geriatric assessment: A feasibility study. Cancer 104:1998-2005, 2005

17. Lindeman RD, Tobin J, Shock NW: Longitudinal studies on the rate of decline in renal function with age. J Am Geriatr Soc 33:278-285, 1985

18. Reuben DB, Rubenstein LV, Hirsch SH, et al: Value of functional status as a predictor of mortality: Results of a prospective study. Am J Med 93:663669, 1992 
19. Stewart $A L$, Ware JE Jr: Measuring Functioning and Well-Being: The Medical Outcomes Study Approach. Durham, NC, Duke University Press, 1992

20. Fillenbaum GG, Smyer MA: The development, validity, and reliability of the OARS multidimensional functional assessment questionnaire. $J$ Gerontol 36:428-434, 1981

20a. Zigmond AS, Snaith RP: The hospital anxiety and depression scale. Acta Psychiatr Scand 67:361370, 1983

21. Loprinzi CL, Laurie JA, Wieand HS, et al: Prospective evaluation of prognostic variables from patient-completed questionnaires: North Central Cancer Treatment Group. J Clin Oncol 12:601-607 1994

21a. Sherbourne CD, Stewart AL: The MOS social support survey. Soc Sci Med 32:705-714, 1991

22. Podsiadlo D, Richardson S: The timed "Up \& Go": A test of basic functional mobility for frail elderly persons. J Am Geriatr Soc 39:142-148, 1991

23. Kawas C, Karagiozis $H$, Resau $L$, et al: Reliability of the Blessed Telephone InformationMemory-Concentration Test. J Geriatr Psychiatry Neurol 8:238-242, 1995

24. National Comprehensive Cancer Network: NCCN Practice Guidelines in Oncology, 2010. http://www .nccn.org/professionals/physician_gls/f_guidelines.asp
25. National Cancer Institute Common Terminology Criteria for Adverse Events (CTCAE), Version 3.0. http://ctep.cancer.gov/protocoldevelopment/ electronic_applications/docs/ctcaev3.pdf

26. Cockcroft DW, Gault MH: Prediction of creatinine clearance from serum creatinine. Nephron 16:31-41, 1976

27. Jelliffe RW: Estimation of creatinine clearance when urine cannot be collected. Lancet 1:975-976, 1971

28. Levey AS, Bosch JP, Lewis JB, et al: A more accurate method to estimate glomerular filtration rate from serum creatinine: A new prediction equationModification of Diet in Renal Disease Study Group. Ann Intern Med 130:461-470, 1999

29. Wright JG, Boddy AV, Highley M, et al: Estimation of glomerular filtration rate in cancer patients. Br J Cancer 84:452-459, 2001

30. Youden WJ: Index for rating diagnostic tests. Cancer 3:32-35, 1950

31. Hocking RR, Leslie RN: Selection of the best subset in regression analysis. Technometrics 9:531540, 1967

32. Hosmer DW, Lemeshow S: Applied Logistic Regression. New York, NY, Wiley, 2000

33. Concato J, Feinstein AR, Holford TR: The risk of determining risk with multivariable models. Ann Intern Med 118:201-210, 1993
34. Walter LC, Brand RJ, Counsell SR, et al: Development and validation of a prognostic index for 1-year mortality in older adults after hospitalization. JAMA 285:2987-2994, 2001

35. Hastie $T$, Tibshirani R, Friedman J (eds): The Elements of Statistical Learning: Data Mining, Inference, and Prediction (ed 2). New York, NY, Springer, 2009

36. Olsen DL, Denlen D (eds): Advanced Data Mining Techniques. New York, NY, Springer, 2008

37. Dees EC, O'Reilly S, Goodman SN, et al: A prospective pharmacologic evaluation of age-related toxicity of adjuvant chemotherapy in women with breast cancer. Cancer Invest 18:521-529, 2000

38. Gómez $H$, Hidalgo M, Casanova $L$, et al: Risk factors for treatment-related death in elderly patients with aggressive non-Hodgkin's lymphoma: Results of a multivariate analysis. J Clin Oncol 16:2065-2069, 1998

39. Repetto L, Carreca I, Maraninchi D, et al: Use of growth factors in the elderly patient with cancer: A report from the Second International Society for Geriatric Oncology (SIOG) 2001 meeting. Crit Rev Oncol Hematol 45:123-128, 2003

40. Izaks GJ, Westendorp RG, Knook DL: The definition of anemia in older persons. JAMA 281: 1714-1717, 1999 